\title{
Eficiência Produtiva Regional da Agricultura Brasileira: uma análise de fronteira estocástica ${ }^{1}$
}

\author{
Clauber Eduardo Marchezan Scherer ${ }^{2}$ e Alexandre Alves Porsse ${ }^{3}$
}

Resumo: O objetivo deste estudo é analisar a eficiência produtiva da agricultura em escala microrregional usando técnicas de estimação de fronteiras de produção estocásticas e análise exploratória de dados espaciais. As estimações foram feitas para as lavouras permanentes e temporárias separadamente com dados do Censo Agropecuário 2006. Os resultados da equação de produção mostram que os fatores produtivos área de terra e trabalho representam ganhos de produtividade para essas lavouras ligados aos retornos crescentes de escala e à intensidade tecnológica. Os resultados também indicam que a relação entre eficiência e especialização é positiva nas lavouras permanentes e negativa nas lavouras temporárias. Fatores geográficos relacionados com precipitações, temperatura e biomas se mostraram mais relevantes para explicar os diferenciais regionais de eficiência das lavouras temporárias. A análise espacial aplicada à lavoura permanente identificou clusters de alta eficiência nas regiões Nordeste e Sul e um núcleo de baixa eficiência na região Norte. Para as lavouras temporárias, destacam-se poucos clusters de alta eficiência situados nas regiões Nordeste e Sudeste e áreas extensas de baixa eficiência situadas predominantemente no Nordeste e Norte do Brasil.

Palavras-chaves: Agricultura, produtividade regional, fronteira de produção estocástica, análise de dados espaciais.

Abstract: This study aims to analyze the regional productive efficiency of agriculture using estimation techniques of stochastic production frontiers and exploratory spatial data analysis. The estimation was carried out for permanent and temporary crops separately using data from 2006 Agricultural Census. The results of production equation show that productive factors such as land area and labor promote productivity gains to those crops

1. Data de submissão: 16 de março de 2015. Data de aceite: 27 de abril de 2017.

2. Doutorando em Economia no Centro de Desenvolvimento e Planejamento Regional da Universidade Federal de Minas Gerais (Cedeplar/UFMG) e Mestre em Economia pelo Programa de Pós-graduação em Desenvolvimento Econômico da Universidade Federal do Paraná (PPGDEUFPR). Belo Horizonte, Minas Gerais, Brasil. E-mail: clauberscherer@gmail.com

3. Professor Adjunto do Departamento de Economia e do Programa de Pós-graduação em Desenvolvimento Econômico da Universidade Federal do Paraná (PPGDE-UFPR). Curitiba, Paraná, Brasil. E-mail: porsse@gmail.com 
related to respectively increase returns to scale and technological intensity. Results also show that the linkage between efficiency and specialization is positive for permanent crops but negative for temporary crops. Additionally, the efficiency of temporary crops seems more sensitive to geographical factors as precipitations, temperature and biomes. The spatial analysis applied to permanent crops identified high efficiency clusters in Northeast and South and low efficiency clusters in the North. Considering temporary crops, it was identified high efficiency clusters in Northeast and Southeast and low efficiency clusters concentrated in North and Northeast of Brazil.

Key-words: Agriculture, regional productivity, stochastic production function, data spatial analysis.

DOI - http://dx.doi.org/10.1590/1234-56781806-94790550210

Classificação JEL: C61, Q12, R12.

\section{Introdução}

O Brasil figura como importante player mundial nos produtos do agronegócio, sendo apontado, inclusive, como referência em termos de processo produtivo e técnicas empregadas. Porém, devido à imensa heterogeneidade existente ao longo do território nacional, essa excelência certamente não é compartilhada por todas as regiões, isto devido, dentre outros fatores, à incapacidade produtiva e também aos fatores característicos dos locais que impossibilitam maiores retornos. Conforme Moreira et al. (2005, p. 07), existem produtores eficientes de todos os tipos, o que sugere que a produtividade não é necessariamente decrescente com o tamanho das propriedades. O que importa é o tipo de tecnologia empregada, a qualidade do gerenciamento e as vantagens competitivas desenvolvidas através do tempo. Nesta descrição, o mecanismo de solução para eventuais disparidades é a identificação dos determinantes múltiplos da produtividade e das restrições que a limitam.

Ainda que ao longo da história econômica exista certa divergência sobre qual o papel desempenhado pela agricultura no processo de desenvolvimento, existe certo consenso em afirmar que a mesma desempenha papel relevante ao criar segurança alimentar, diminuindo a exposição dos mais pobres à fome, e ao gerar exce- dentes que são importantes para o crescimento industrial. Dado isto, chega-se a outro questionamento importante, que diz respeito à condução e ao aprimoramento do setor. Johnston e Mellor (1961, p. 570) chamam atenção para o fato de que o reconhecimento das características pertinentes ao processo de desenvolvimento agrícola é essencial para a formulação de estratégias que aumentem o produto e a produtividade do setor, o que, em última análise, leva à otimização da utilização dos fatores de produção, auxiliando, assim, no desenvolvimento econômico local.

Da mesma forma, para a obtenção de um crescimento robusto que incentive o desenvolvimento de forma não concentradora, também é preciso analisar a produtividade agrícola sob o aspecto espacial. Ferranti et al. (2005, p. 112) chamam a atenção para o fato de a distribuição espacial dos fatores de produção estar relacionada a elementos que determinam o desenvolvimento econômico e, consequentemente, o desempenho regional. Isso acaba gerando uma espécie de armadilha, em que regiões mais ricas tendem a apresentar trabalhadores com maiores níveis de produtividade, melhor infraestrutura e demais elementos que dão margem a melhores condições de vida, atraindo, assim, pessoas das regiões menos desenvolvidas, gerando pressões demográficas e o aprofundamento das disparidades espaciais. 
Dessa forma, o que se pretende nesse trabalho é entender e caracterizar melhor o desempenho produtivo agrícola das diferentes microrregiões brasileiras e seus potenciais impactos em termos de desenvolvimento regional. Isso será feito a partir da mensuração de eficiência, através da técnica de fronteiras estocásticas de produção, que procura ranquear os dados de forma a identificar aqueles locais que fazem melhor combinação possível dos insumos produtivos, dada uma função de produção. Neste trabalho, os modelos de função de produção estocástica serão estimados para as lavouras permanentes e temporárias, com informações de microrregiões obtidas do Censo Agropecuário 2006 (Segunda Apuração). A partir deles, geram-se indicadores de eficiência regional que são analisados por meio da técnica de análise exploratória de dados espaciais para identificar padrões de distribuição espacial da eficiência ao longo do território para esses dois tipos de culturas agrícolas.

Para isso, este trabalho conta, além dessa introdução, com mais quatro seções. Na segunda além de uma rápida apresentação de dados sobre o setor agropecuário brasileiro, é feita uma revisão de literatura de trabalhos voltados para a análise da produtividade do setor, bem como acerca das fronteiras de produção estocásticas; a seção três descreve os materiais e métodos, destacando a construção das variáveis utilizadas e as estratégias de estimação; na seção quatro são apresentados os resultados por tipos de lavouras, seguida pela seção cinco, que traz os apontamentos finais do trabalho.

\section{Revisão de literatura}

\subsection{O setor agropecuário brasileiro}

A agricultura tem sido apontada como um caso de sucesso produtivo, inclusive dando destaque ao Brasil como um dos maiores players globais do setor. Sua competitividade internacional é notável em muitas culturas. A produtividade da agricultura avança revelada pelo aumento da produção sem correspondente aumento proporcional da área plantada, ao mesmo tempo em que se solidifica a expansão agrícola que atingiu a região Centro-Oeste e, mais recentemente, Norte. Conforme observado por Felema et al. (2013), a absorção de novas tecnologias - por meio da incorporação de técnicas e equipamentos - proporcionou novo dinamismo para a agricultura, fomentando a produtividade e dinamismo desse setor no País.

Quando observados os dados censitários relacionados à evolução do setor agropecuário, percebe-se que, na história econômica brasileira, ao longo do processo de industrialização, a agricultura perdeu espaço no quantum da economia, como pode ser observado na Tabela 1. A diminuição do número de trabalhadores no campo, conforme observam Gasques et al. (2009), além do processo de crescimento das cidades, está relacionado também a um processo conjunto de mecanização e ganho tecnológico do setor, fatores que podem ser notados a partir da evolução do número de tratores médios na agricultura brasileira, conforme a tabela a seguir, pois se num primeiro momento o número desse maquinário cresce, com o tempo, menos tratores passam a fazer um trabalho em que antes eram requeridas mais máquinas.

Os dados, indiretamente, também refletem duas grandes expansões de áreas destinadas a lavouras com impactos importantes sobre a dinâmica regional brasileira. Uma entre 1970 e 1980, como resultado da expansão para o CentroOeste, e outra ocorrida a partir de 1995, fruto de uma expansão em direção ao Norte, conforme notado por Gasques et al. (2009).

Quando observadas as principais culturas a partir dos dados do Censo Agropecuário 2006, a partir da sua contribuição para o valor adicionado (Figura 1), percebe-se o forte predomínio das culturas pelas quais o Brasil está entre os líderes mundiais de exportações, como café, banana e laranja, nas culturas permanentes, e principalmente a soja e a cana-de-açúcar na classe dos produtos da lavoura temporária. Esses números levantam questões importantes para o 
Tabela 1. Evolução da agricultura a partir dos dados censitários

\begin{tabular}{lcccccccc}
\hline \multicolumn{1}{c}{ Variável } & $\mathbf{1 9 2 0}$ & $\mathbf{1 9 4 0}$ & $\mathbf{1 9 5 0}$ & $\mathbf{1 9 6 0}$ & $\mathbf{1 9 7 0}$ & $\mathbf{1 9 8 0}$ & $\mathbf{1 9 9 5}$ & $\mathbf{2 0 0 6}$ \\
\hline Estabelecimentos (Índices) & 100 & 294 & 319 & 515 & 760 & 796 & 750 & 798 \\
Área de Lavoura (Índices) & 100 & 284 & 287 & 432 & 512 & 869 & 754 & 901 \\
Área Produtiva em Relação ao Total do Estabelecimento & 3,79 & 9,53 & 8,22 & 11,49 & 11,55 & 15,82 & 14,17 & 18,14 \\
Média de Pessoal Ocupado por Estabelecimento & 9,74 & 5,33 & 5,33 & 4,68 & 3,57 & 4,1 & 3,69 & 3,20 \\
Média de Área de Lavoura (ha) por Trator & 3893,35 & 5572,61 & 2280,82 & 468,04 & 204,88 & 105,88 & 62,65 & 72,92 \\
\hline
\end{tabular}

Nota: A área produtiva do estabelecimento é definida como a participação de terras utilizadas na agricultura em relação ao tamanho da propriedade. Por sua vez, da relação entre área produtiva do estabelecimento e número total de tratores, computa-se a média de tratores por hectares.

Fonte: Adaptado de Gasques et al. (2009).

desenvolvimento do País: apesar de sua adaptabilidade, essas culturas não podem ser cultivadas em todas as regiões, o que, a partir da constatação de seu grande valor adicionado frente às demais, tende a acentuar problemas relacionados à concentração regional, uma vez que as três principais culturas (tanto permanentes como temporárias) representaram praticamente $75 \%$ do valor de produção para 2006, como fica evidenciado na Figura 1.

Nesse sentido, Perobelli et al. (2007) identificam, ao analisarem a produtividade agrícola brasileira (nos anos de 1991, 1997, 2003), uma forte presença de autocorrelação espacial no setor, sendo territorialmente concentrada (e persistente) a presença de dois clusters de alta produtividade no Brasil: um que vai das regiões Sudeste e Centro-Oeste e outro no litoral nordestino. Da mesma forma, Marinho e Carvalho (2004) destacam que, regionalmente, para 1970 e 1985, as áreas mais eficientes encontravam-se sobretudo no Sul e no Sudeste.

Outra questão a ser levada em conta é o grau de concentração fundiária no Brasil, o que pode fazer com que resultados relacionados ao bom desempenho comercial do setor sejam na verdade mascarados, uma vez que a heterogeneidade estrutural do setor, em que novas tecnologias não são absorvidas no processo produtivo uniformemente entre produtores, faz com que poucas unidades realmente se apropriem dos ganhos, conforme destacado por Fornazier e Vieira Filho (2012). Esse fato pode ter contornos ainda mais importantes no Brasil, onde existe um

Figura 1. Participação das principais culturas no valor de produção

\section{Lavouras permanentes}

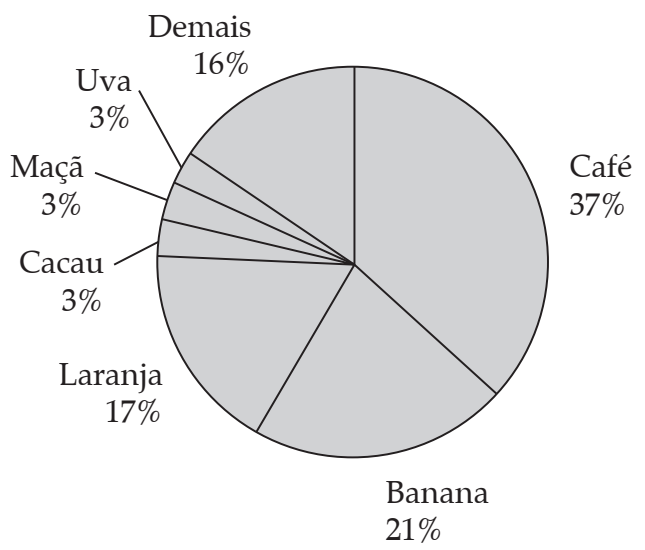

Lavouras temporárias

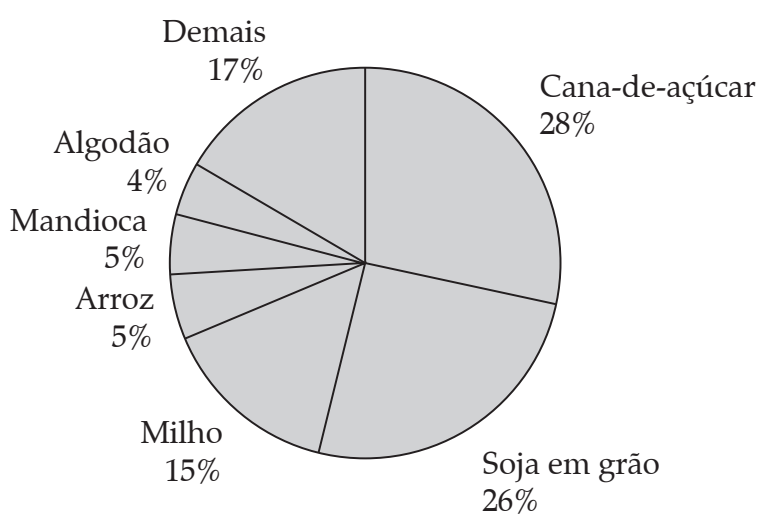

Fonte: Censo Agropecuário 2006. 
predomínio de pequenas propriedades com agricultura de pequena escala e que tradicionalmente não se caracterizam por participar no comércio internacional.

Nesse sentido, Helfand et al. (2015) destacam, a partir do Censo Agropecuário 2006, que das mais de 5 milhões de propriedades agrícolas no País, cerca de $90 \%$ delas - ou 4,5 milhões - tinham menos de 100 hectares, sendo que os $2 \%$ das propriedades com mais de 500 hectares foram responsáveis por $56 \%$ da área produzida total pelo setor. Além disso, em termos regionais, a heterogeneidade espacial do País é reforçada, uma vez que, por exemplo, enquanto o Nordeste concentrava mais de metade das propriedades com até 5 hectares, no Centro-Oeste, $81 \%$ da terra é gerida por propriedades com mais de 500 hectares. Assim, os autores chamam atenção para o fato de que a interpretação do resultado do crescimento médio da produtividade total dos fatores de $5 \%$ ao ano entre 1985 e 2006 obtidos, deve ser feita com bastante cuidado.

Levando isso em conta, para analisar, ainda que de forma exploratória, a correlação entre agricultura e padrão de desenvolvimento regional no Brasil, buscou-se organizar e caracterizar as microrregiões brasileiras em termos do seu nível de renda per capita, bem como sua estrutura produtiva, com particular interesse sobre o peso da atividade agropecuária ${ }^{4}$. Primeiramente, a partir dos dados de valor adicionado e pessoal ocupado por setores da economia (esses últimos obtidos junto aos Censos Demográficos 2000 e 2010), foi construído um indicador de dinâmica regional, em que os dados de renda per capita no período inicial foram confrontados com os dados da variação real do valor no período (2000-2010). Assim, tem-se um indicador que aponta se a microrregião foi estática no sentido de manter o padrão de renda per capita, ou se a mesma apresentou algum tipo de dinâmica (moveu-se acima/ abaixo da média). De posse desses valores, os resultados foram normalizados em uma escala de

4. Como os dados do PIB Municipal do IBGE foram utilizados, não foi possível avaliar isoladamente o setor agrícola.
0 a 1 , na qual o valor 0,5 passa a ser o ponto médio do PIB per capita nos dois períodos, de forma que seja possível a identificação de quatro cenários distintos para as microrregiões (Figura 2).

Com essa tipologia desenvolvida, é possível construir uma caracterização qualitativa dos dados, seguindo os quadrantes do gráfico, em que no primeiro quadrante estão as regiões ricas e dinâmicas (RR), no segundo, as pobres e dinâmicas (PR), no terceiro, as pobres não dinâmicas (PP) e no quarto, as ricas não dinâmicas (RP). A seguir são apresentados alguns dados para cada grupo de microrregiões, seguindo essa tipologia com o objetivo de compreender a importância econômica de cada um, bem como a composição setorial da sua produção.

Via de regra, percebe-se uma forte concentração das regiões próximas à origem no gráfico, o que, em outras palavras, aponta para uma persistência do padrão de renda per capita abaixo da média ao longo do tempo analisado. Essa situação, em termos de desenvolvimento regional, caracteriza um processo de manutenção do padrão de disparidades regionais, uma vez que grande parte das regióes está concentrada na área do terceiro quadrante.

Conforme os dados da Tabela 2, percebe-se forte concentração regional, já que $80 \%$ das microrregiões são responsáveis por não mais que $31 \%$ do valor adicionado. Além disso, o que é mais grave em termos regionais é a notável persistência dessa distribuição, uma vez que o número de microrregiões que eram pobres e passaram a ser ricas é muito pequeno e se equipara ao número de microrregiões que eram ricas e passaram a ser pobres $(3 \%)$.

Os dados da Tabela 3 permitem caracterizar as economias dessas regiões a partir de sua composição de valor adicionado por atividades da economia. Esse exercício é importante para compreender qual o perfil produtivo interno, conforme a estrutura de cada região a partir da tipologia proposta. Tal análise é interessante no sentido de apontar se alguma diferenciação em termos estruturais pode estar relacionada ao tipo de estrutura encontrada. Como resultado geral, 
Figura 2. Dinâmica microrregional de riqueza (2000-2010)

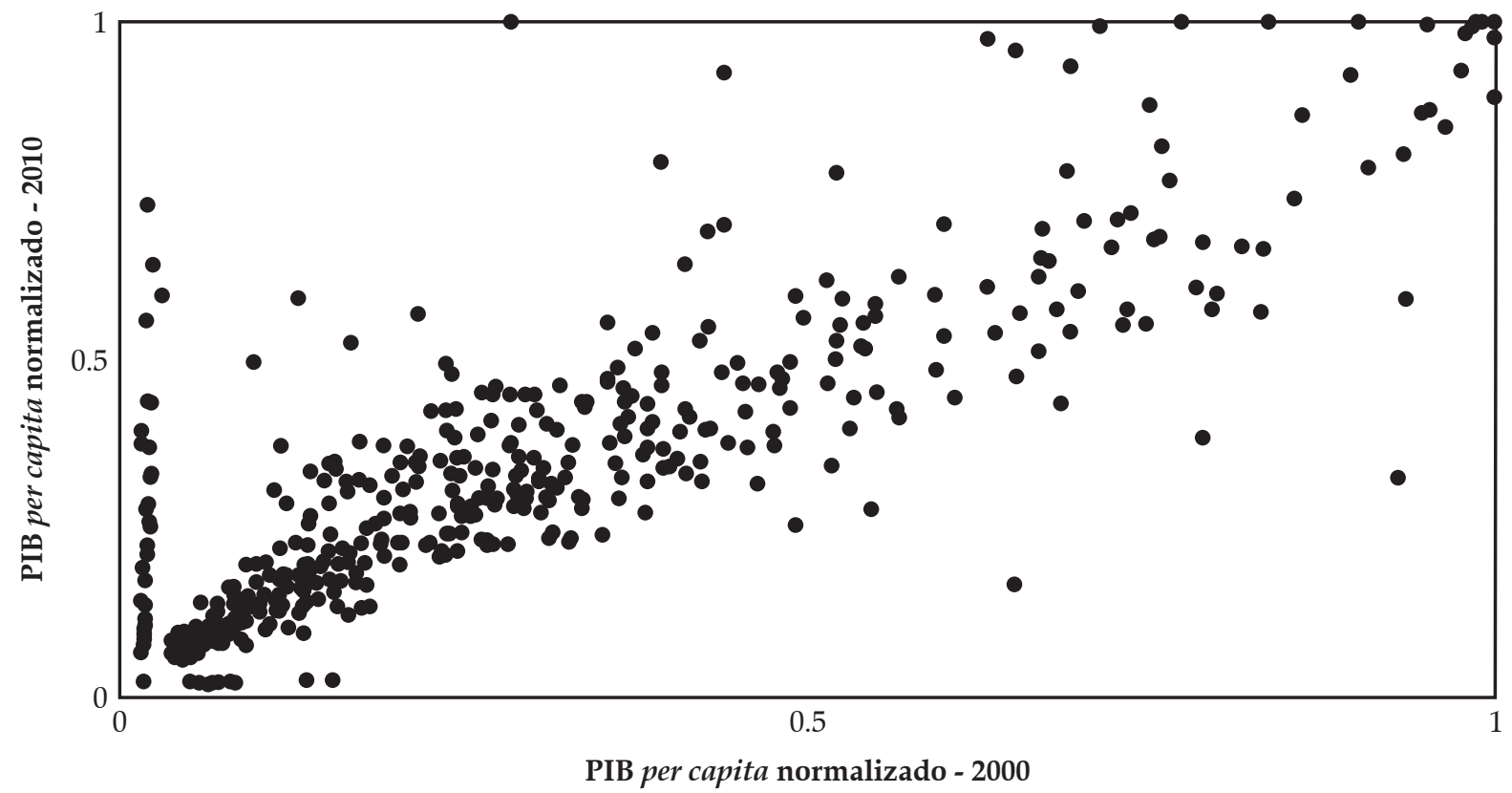

Fonte: Resultados de pesquisa.

Tabela 2. Participação no Valor Adicionado (VA) a partir da classificação das microrregiões

\begin{tabular}{lccc}
\hline \multicolumn{4}{c}{ Classificação das microrregiões segundo o nível de desenvolvimento: composição percentual } \\
\hline Número de Microrregiões (\%) & VA 2000 (\%) & VA 2010 (\%) \\
\hline - PP & 80 & 30.6 & 33.1 \\
$2-$ RR & 13 & 65.3 & 62.7 \\
$3-$ PR & 3 & 1.5 & 2.1 \\
$4-$ RP & 3 & 2.6 & 2.2 \\
Total geral & 100 & 100 & 100 \\
\hline
\end{tabular}

Fonte: Resultados de pesquisa.

Tabela 3. VA setorial a partir da classificação das microrregiões (\%)

\begin{tabular}{lcccccc}
\hline & \multicolumn{2}{c}{ Agropecuária } & \multicolumn{2}{c}{ Indústria } & \multicolumn{2}{c}{ Serviços } \\
\hline $1-\mathrm{PP}$ & $\mathbf{2 0 0 0}$ & $\mathbf{2 0 1 0}$ & $\mathbf{2 0 0 0}$ & $\mathbf{2 0 1 0}$ & $\mathbf{2 0 0 0}$ & $\mathbf{2 0 1 0}$ \\
$2-\mathrm{RR}$ & 12.3 & 10.8 & 20.8 & 21.9 & 64.3 & 64.9 \\
$3-\mathrm{PR}$ & 1.5 & 1.5 & 30.2 & 30.7 & 67.7 & 67.7 \\
$4-\mathrm{RP}$ & 18.2 & 11.3 & 23.8 & 35.0 & 57.9 & 51.5 \\
Total geral & 4.7 & 4.6 & 33.3 & 31.4 & 59.5 & 63.4 \\
\hline
\end{tabular}

Fonte: Resultados de pesquisa. 
nota-se que aquelas microrregiões que apresentam menor renda e são menos dinâmicas (grupo PP) estão relacionadas a uma maior participação do setor agropecuário em suas economias. Ainda que tenham em serviços sua maior participação (muito em função do peso exercido pela Administração Pública), nessas regiões o desempenho tende a ser fortemente relacionado ao do setor agropecuário, uma vez que são, predominantemente, regiões de pequeno porte e que não apresentam um setor industrial desenvolvido, tornando o setor agropecuário central para a economia local.

De maneira geral, o que pode ser percebido a partir dessa análise exploratória é a presença de uma relativa concentração, tanto da atividade principal desenvolvida na agricultura, quanto de estagnação em termos de crescimento de renda per capita. Além disso, nota-se também que o setor agropecuário está mais presente naquelas regiões mais pobres. Cabe, então, explorar se as regiões notadamente mais pobres estão de alguma forma associadas a uma menor eficiência do setor agrícola, de modo que tal correlação pode auxiliar na formulação de políticas voltadas ao aumento da eficiência produtiva agrícola e, por consequência, da produtividade total nessas regiões.

Ainda que exista uma literatura voltada para o tema da eficiência da agricultura, são poucos os trabalhos que procuram mensurar sua eficiência por meio de métodos estocásticos. Dentre esses casos destacam-se os já citados estudos de Marinho e Carvalho (2004), que trabalham com uma escala espacial agregada ao nível dos estados; Schimidt et al. (2009), que utilizam somente os municípios da região Centro-Oeste como escala espacial de análise e Helfand et al. (2015), que analisam o padrão de eficiência segundo o porte das propriedades. No presente estudo, avalia-se a eficiência da agricultura tomando-se as microrregióes como escala territorial de análise e segmentando a investigação para as culturas permanentes e temporárias. Busca-se, assim, identificar se a eficiência da agricultura tem um padrão de dependência espacial, aspecto ainda não explorado na literatura que utiliza modelos de fronteira estocástica e que pode ser relevante na compreensão dos diferenciais de eficiência produtiva nas lavouras permanentes e temporárias.

\subsection{Mensuração da eficiência produtiva usando funções de produção estocástica}

A partir da década de 1950 ampliam-se os estudos inspirados na análise microeconômica e voltados à produção de medidas de eficiência relacionando as firmas e sua capacidade no uso de insumos na produção, no que se conhece por produtividade total dos fatores. Conforme Kumbhakar e Lovell (2003, p. 2), nem todos os produtores são bem-sucedidos na utilização da menor quantidade possível de insumos para obter-se a otimização de produto, dada a tecnologia disponível. Em outras palavras, nem todos os produtores são tecnicamente eficientes.

Conforme destacado por Coelli et al. (2005), a eficiência técnica pode ser entendida como o modo em que uma combinação ótima de insumos é empregada no processo produtivo com o intuito de obter o produto máximo. Na Figura 3 é possível observar duas óticas de mensuração da eficiência. Na primeira delas (a), uma firma que produza dois produtos Y1 e Y2 utilizando um único insumo $X 1$, será eficiente no ponto $B^{\prime}$, em que sua curva de possibilidade de produção $Z^{\prime}$ tangencia sua isoreceita $\mathrm{DD}^{\prime}$. Alternativamente, no caso (b), sendo X1 e X2 dois insumos utilizados na obtenção de uma unidade do produto $Y$, haverá eficiência alocativa quando a combinação dos insumos estiver situada no ponto em que essa reta tangencia a isoquanta $\mathrm{SS}^{\prime}$, no caso do gráfico, o ponto $Q^{\prime}$. Apesar de serem similares, a vantagem da abordagem do produto frente à do insumo, é que nela não são necessárias informações referentes aos custos dos insumos, de tal forma que a estimação da medida de eficiência técnica analisada no presente trabalho seguirá essa abordagem.

Até o surgimento dos estudos que inauguraram a tradição de mensuração de eficiência técnica a partir de funções de produção estocásticas, os desvios da fronteira (como os pontos B e Q) 
Figura 3. Fronteira de possibilidade de produção orientada para produto (a) e insumo (b)

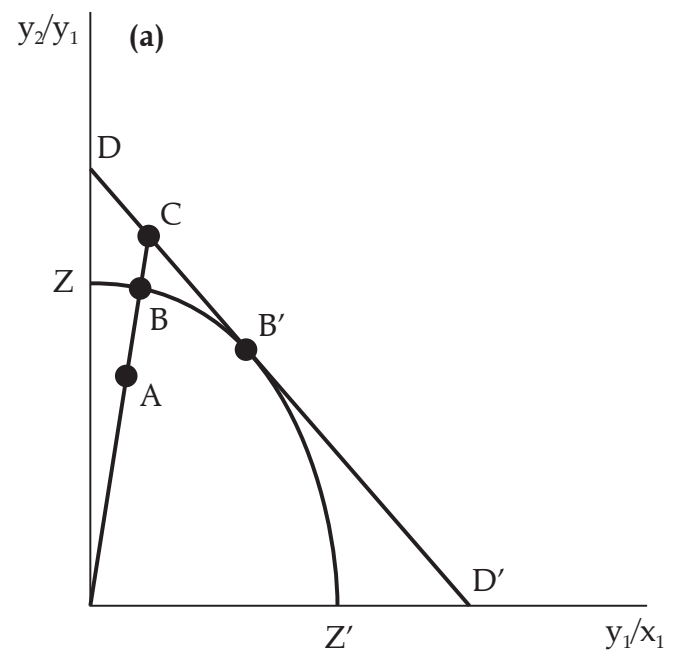

Fonte: Apud Coelli et al. (2005).

eram associados à ineficiência técnica de forma determinística, sem distingui-la de eventuais erros aleatórios. Meeusen e Van den Broeck (1977) e Aigner et al. (1977) propuseram, então, considerar uma função da distribuição estatística para os desvios de fronteira representados pelo termo de erro. Enquanto os primeiros propuseram a distribuição exponencial, os últimos utilizaram a half-normal. Jondrow et al. (1982) adaptaram as propriedades estatísticas do modelo de forma a possibilitar a estimação da eficiência individual - e não só um parâmetro médio, como era o caso até então -, o que permitiu um ordenamento individual da eficiência.

Desde então, contribuições marginais têm sido dadas ao método, tornando sua utilização cada vez mais flexível e também mais ampla. Dentre os avanços, destaca-se Battese e Coelli (1995), que adaptaram o modelo de forma a incorporar variáveis explanatórias no termo de erro atribuído à ineficiência. Assim, foi possível não só o uso de variáveis condicionantes da função de produção, como também aquelas condicionantes do termo de ineficiência, as quais seriam associadas a distúrbios nos resultados de eficiência. $\mathrm{Na}$ formalização de Battese e Coelli (1995), para o caso de cross-section, tem-se:

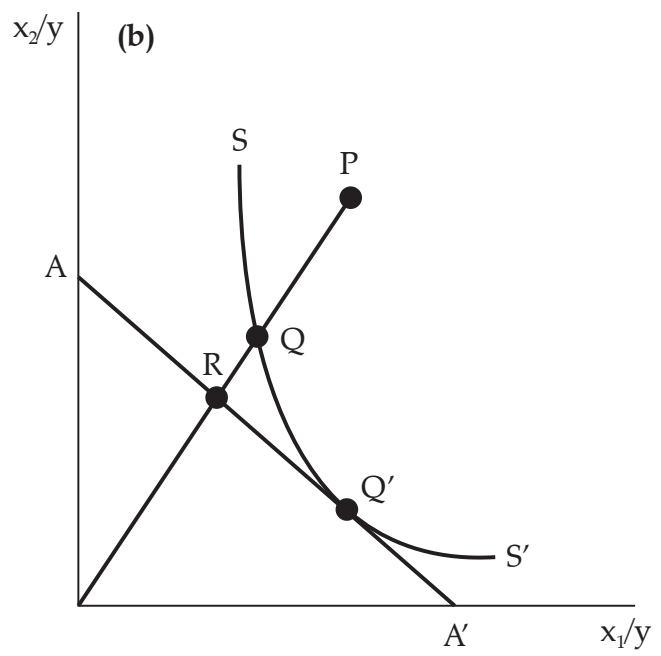

$$
\begin{aligned}
& y_{i}=e^{\left(x_{i} \beta+v_{i}-u_{i}\right)}=e^{\left(x_{i} \beta+v_{i}\right)} e^{\left(-u_{i}\right)} \\
& \ln y_{i}=x_{i} \beta_{i}+v_{i}-u_{i}
\end{aligned}
$$

Em que $y$ representa a quantidade produzida pela unidade $i, x$ é o vetor de insumos utilizado e $\beta$ é o vetor de coeficientes a ser estimado e que define a tecnologia empregada na produção. A grande contribuição do modelo fica por conta dos termos $v_{i}$ e $u_{i}$, que representam componentes distintos do erro: $v_{i}$ é a parte aleatória do erro com $v_{i}$ iid $\sim N(0 ; 1)$; já $u_{i} \geq 0$, que é iid $\sim N^{+}\left(\mu ; \sigma_{u}^{2}\right),{ }^{5}$ mede a ineficiência na função de produção. Assim, caso $u_{i}$ seja estatisticamente diferente de zero ${ }^{6}$, há presença de ineficiência técnica. Conforme Battesi e Coelli (1995), esse termo é definido como segue:

$$
u_{i}=z_{i} \delta+\omega_{i}
$$

Em que $\delta$ capta fatores que influenciam a eficiência de forma indireta - não relacionados aos insumos de produção -, ou seja, estão no termo de erro, mas não são aleatórios. O termo $\omega_{i}$ representa distúrbios estritamente aleatórios.

5. As mesmas propriedades da distribuição half-normal são válidas para a normal truncada, exponencial e gamma.

6. Essa hipótese é verificada por meio de um teste de restrição em que a hipótese nula é de que $u_{i}=v_{i}$ 
Dessa forma, quanto mais eficiente for a utilização dos insumos para a produção, mais próximo de 0 se encontrará o valor de $u_{i}$. Vale destacar, ainda, que a estimação se dá de forma simultânea a partir das equações (2) e (3) por meio do método de máxima verossimilhança aplicado em três passos. ${ }^{7}$ Assim, se constatada a presença de um termo de erro não aleatório $u_{i}$ esse é modelado conjuntamente à função de produção.

\section{Materiais e métodos}

Esta seção apresenta, inicialmente, as variáveis utilizadas na estimação do modelo de Fronteira de Produção Estocástica (FPE). Em seguida, descreve-se o modelo de estimação e a técnica de análise exploratória de dados espaciais utilizada para avaliar o padrão de distribuição espacial da eficiência da agricultura.

\subsection{Variáveis do Modelo FPE}

As informações para construção das variáveis foram obtidas majoritariamente a partir do Censo Agropecuário 2006, sendo algumas variáveis como especialização ${ }^{8}$, precipitação e clima colhidas junto ao Ipeadata, enquanto a informação relacionada a biomas foi obtida junto ao IBGE. Essas variáveis são descritas abaixo.

- $Q_{i}$ : variável dependente quantidade produzida, construída a partir de um índice de quantum calculado para as lavouras permanente e temporária separadamente no qual a estrutura de ponderação é baseada no valor adicionado de cada produto;

7. Para mais detalhes sobre o método de estimação, ver Coelli (1996).

8. Indiretamente, essa variável pode ser atribuída ao Censo, uma vez que esta é a fonte dos dados brutos para sua construção.

9. $Q_{i}=\sum_{i} W_{j}^{i} Q_{j}^{i}$ onde $i$ é a microrregião; $j$ é o produto; $Q_{j}^{i}$ é a quantidade em $i$ de $j ; W_{j}^{i}$ é o fator de ponderação dado por $W_{j}^{i}=\frac{V_{j}^{i}}{\sum_{j=1}^{n} V_{j}^{i}}$, em que $V_{j}^{i}$ é o valor adicionado de $i$ para o produto $j$;
- $A_{i}$ : área em hectares colhida por estabelecimento em cada tipo de lavoura;

- $K_{i}$ : variável proxy para a mecanização, construída pela composição entre tratores e demais maquinários empregados a partir de uma análise de componentes principais (atribuiu-se um peso de $90 \%$ para tratores e $10 \%$ para demais máquinas);

- $T_{i}$ : total de empregados declarados para o Censo divididos por tipo de lavoura ${ }^{10}$;

- $F_{i}$ : total em milhares de reais dos financiamentos obtidos por tipo de lavouras;

- $E S P_{i}$ : índice de especialização, o qual utiliza como fator de ponderação o valor total de produção das respectivas culturas (o índice varia entre 0 e 1 , sendo que, quanto mais próximo de 1 , maior a concentração produtiva naquela microrregião) ${ }^{11}$;

- $E S C_{k i}$ : escolaridade do dirigente do estabelecimento dividida em três grupos, sendo $k=$ ensino fundamental, médio e superior completos. Essas informações são disponibilizadas por estabelecimentos, sendo atribuído apenas um valor para os mesmos, independente do número de administradores ali existentes;

- $P R E C_{e i}$ : precipitação média em milímetros por estações do ano nas microrregiões, sendo $e=$ verão, outono, inverno e primavera;

- $C L I_{j i}$ : temperatura média em graus celsius por estações do ano nas microrregiões, sendo $j=$ verão, outono, inverno e primavera;

- $B O_{l i}$ : variável dummy que contém a classificação das microrregióes conforme a distribuição de biomas no território, sendo $l=$ Mata Atlântica, Amazônia, Cerrado, Caatinga, Pantanal e Pampa (variável omitida).

10. Os dados disponibilizados são de número bruto, sem distinção de grupo de escolaridade ou rendimento salarial.

11. $E S P_{i}=\frac{1}{2} \sum_{j=1}^{n}\left|\frac{X_{p j}}{X_{p}}-\frac{X_{i j}}{X_{i}}\right|$ em que $X_{i j}$ é o valor de produção de $j$ na microrregião $i, X_{i}$ é o total produzido na região $i, X_{p j}$ valor de produção de $j$ no país e $X_{p}$ é o total da produção no país. 
É importante chamar a atenção para a não inclusão de algumas variáveis recorrentes nessa literatura, como o uso de corretivos e agrotóxicos. Por serem fornecidas para as lavouras de modo geral, sem distinção dos tipos de cultura, ou então para estados, a distribuição do uso desses fatores em microrregiões seria ad hoc, podendo gerar vieses.

\subsection{Especificação do modelo FPE}

A estimação econométrica da eficiência produtiva pelo método de FPE pode ser realizada por meio de duas especificações da função de produção: Cobb-Douglas ou Translog. Para esse trabalho, por meio do software Frontier 4.1, a função de produção agrícola utilizada foi a Translog, escolhida a partir dos resultados do teste de razão de verossimilhança, o qual mostrou ser esse modelo o mais adequado. A equação de produção é dada como função da área, mecanização, trabalhadores e financiamentos, além do termo de erro que tem duas partes:

$$
\begin{aligned}
& \ln Q_{i}=\beta_{0}+\Sigma_{k} \beta_{k} \ln X_{k i}+\Sigma_{k} \gamma_{k} \frac{1}{2} \ln X_{k i}^{2}+ \\
& +\Sigma_{k} \theta_{k} \frac{1}{2} \ln X_{k i} \ln Z_{k^{*} i}+V_{i}-U_{i}
\end{aligned}
$$

Em que $X_{i}=\left[A_{i}, K_{i}, T_{i}, F_{i}\right], Z_{i}$ contém os elementos de $X_{i}$ exclusive o k-ésimo elemento e $U_{i}$ é o termo de erro normal-truncado representativo da medida de ineficiência técnica no modelo, o qual é desmembrado do termo de erro normal $V_{i}$. O termo $U_{i}$ capta fatores não relacionados diretamente àqueles que seriam insumos da produção, mas que, mesmo assim, exercem efeito indireto sobre a ineficiência agrícola das microrregiões.
Nesse trabalho, para captar esses efeitos indiretos, a equação de ineficiência $U_{i}$ inclui como condicionantes um índice de especialização nas lavouras permanentes e temporárias, a escolaridade de quem dirige o estabelecimento - dividida em três classes -, a precipitação e o clima, a partir das médias por estações, e o bioma no qual está inserira a microrregião. Essa equação tem a seguinte forma:

$$
\begin{aligned}
& U_{i}=\delta_{1} E S P_{i}+\Sigma_{k} \delta_{k} E S C_{k i}+\Sigma_{e} \delta_{e} P R E C_{e i}+ \\
& +\Sigma_{j} \delta_{j} C L I_{j i}+\Sigma_{l} \delta_{l} B I O_{l i}+\omega_{i}
\end{aligned}
$$

Por pressuposto do modelo, assume-se que o termo de ineficiência técnica possui distribuição normal-truncada, o que em grandes amostras permite a inferência estatística dos coeficientes estimados conforme convencionalmente utilizada (testes $t$ de Student). Assim, a partir da estimação simultânea da função de produção com suas fontes indiretas de perturbações não aleatórias (equações 4 e 5), se obtém uma medida de desempenho em termos de ineficiência, identificando-se a contribuição de cada variável sobre a elasticidade do resultado.

Para capturar da melhor forma possível os efeitos das variáveis na medida de ineficiência, é proposta a estimação e comparação de quatro diferentes modelos. Primeiramente faz-se a estimação somente da equação de produção (equação 4) e posteriormente a estimação simultânea das equações de produção e ineficiência, incluindo-se gradativamente os conjuntos de variáveis condicionantes da ineficiência das microrregiões. As especificações desses quatro modelos a serem estimados estão representas na Tabela 4. 
Tabela 4. Descrição da especificação dos modelos FPE

\begin{tabular}{|c|c|c|c|c|}
\hline Variável & Modelo 1 & Modelo 2 & Modelo 3 & Modelo 4 \\
\hline \multicolumn{5}{|l|}{ Equação de Produção } \\
\hline Intercepto & * & * & * & * \\
\hline Ln A & * & * & * & * \\
\hline Ln K & * & * & * & * \\
\hline $\operatorname{Ln} \mathrm{T}$ & * & * & * & * \\
\hline $\begin{array}{l}\text { Ln I } \\
\text { Ln F }\end{array}$ & $*$ & * & * & * \\
\hline $\begin{array}{l}\operatorname{Ln} F \\
\operatorname{Ln} A^{2}\end{array}$ & * & * & $*$ & * \\
\hline $\begin{array}{l}\operatorname{Ln} A^{2} \\
\operatorname{Ln} K^{2}\end{array}$ & * & * & * & * \\
\hline $\operatorname{Ln} K^{2}$ & * & $*$ & * & * \\
\hline $\operatorname{Ln} T^{2}$ & * & * & * & * \\
\hline $\operatorname{Ln~F}^{2}$ & * & * & * & * \\
\hline $\operatorname{Ln} A^{*} \operatorname{Ln} K$ & * & * & * & * \\
\hline $\operatorname{Ln} A^{*} \operatorname{Ln} T$ & * & * & * & * \\
\hline $\operatorname{Ln} A^{*} \operatorname{Ln} F$ & * & * & * & * \\
\hline $\operatorname{Ln} K^{*} \operatorname{Ln} T$ & * & $*$ & * & * \\
\hline $\operatorname{Ln} K^{*} \operatorname{Ln} F$ & * & $*$ & $*$ & * \\
\hline $\operatorname{Ln~T}^{*} \operatorname{Ln} \mathrm{F}$ & & & & \\
\hline \multicolumn{5}{|l|}{ Equação de Ineficiência } \\
\hline Ensino Fundamental & & * & * & * \\
\hline Ensino Médio & & * & * & * \\
\hline Ensino Superior & & * & * & * \\
\hline Especialização & & * & * & * \\
\hline Precipitação Verão & & & * & * \\
\hline Precipitação Outono & & & * & * \\
\hline Precipitação Inverno & & & * & * \\
\hline Precipitação Primavera & & & * & * \\
\hline Temperatura Verão & & & * & * \\
\hline Temperatura Outono & & & * & * \\
\hline Temperatura Inverno & & & * & * \\
\hline Temperatura Primavera & & & * & * \\
\hline Amazônia & & & & * \\
\hline Mata Atlântica & & & & * \\
\hline Caatinga & & & & * \\
\hline Cerrado & & & & * \\
\hline Pantanal & & & & * \\
\hline
\end{tabular}

Fonte: Elaborado pelos autores.

Convém destacar que a medida proposta pelo modelo é a de ineficiência, a qual está diretamente relacionada com a função de produção especificada, ou seja, por mais que os fatos mostrem ser determinada região altamente produtiva (essa medida geralmente atribuída à razão entre toneladas colhidas por área), a região em questão pode não estar fazendo o melhor uso possível dos recursos disponíveis, sendo, assim, uma unidade ineficiente. Dessa forma, a abordagem por FPE pode trazer novos fatos relacionados à agricultura no País.

\subsection{Análise espacial da medida de ineficiência agrícola}

Dentre os objetivos deste trabalho, há o interesse em investigar o padrão de distribuição espacial da medida de ineficiência da agricultura estimada para as lavouras permanentes e temporárias nas microrregiões. Assim, técnicas de análise exploratória de dados espaciais foram aplicadas aos resultados da medida de ineficiência estimados pelos modelos FPE para avaliar se existe algum padrão de homogeneidade ou 
heterogeneidade espacial no índice de eficiência. Essa análise busca identificar "ilhas de ineficiência", as quais poderiam ser alvo de políticas públicas e/ou privadas voltadas ao incremento da eficiência produtiva da agricultura.

Neste trabalho foram feitas análises de dependência espacial global e local univariadas. Conforme Almeida (2012), uma medida de associação global univariada pode ser obtida pelo cálculo da estatística I de Moran, que consiste em um coeficiente de autocorrelação espacial. Esse coeficiente pode ser obtido pela autocovariância espacial de uma variável de interesse em relação a variância dos dados, cuja representação é a seguinte:

$$
I=\frac{z^{\prime} W z}{z^{\prime} z}
$$

Em que $z$ representa os valores padronizados da variável de interesse e $W$ é a matriz de ponderação espacial. A matriz de ponderação espacial utilizada foi do tipo Queen de primeira ordem, a qual considera como vizinhos todas as microrregiões que têm alguma fronteira em comum com determinada microrregião. A hipótese nula do teste é a de aleatoriedade espacial, sendo que a esperança do I de Moran é assintoticamente zero. Segundo Almeida (2012), uma correlação espacial positiva indica que há uma similaridade entre os valores do atributo estudado e da localização espacial do mesmo. Já uma relação negativa indica o oposto, ou seja, lugares com padrão positivo do atributo tendem a estar rodeados de regiões com baixo valor no mesmo.

Contudo, a estatística I de Moran é apenas um indicador global de dependência espacial, não permitindo identificar padrões de heterogeneidade ou homogeneidade específicos no espaço, os chamados clusters ou regimes espaciais. Tal aspecto pode ser avaliado pela aplicação da técnica LISA (Local Indicators of Spatial Association), que consiste em uma estimativa local da estatística de I de Moran conforme definido abaixo:

$$
I_{i}=z_{i} \sum_{j=1}^{J} w_{i j} z_{j}
$$

Em que $I_{i}$ só abrange os vizinhos da região $i$, ponderados conforme a escolha da matriz espacial e $z_{i}$ é o valor padronizado da variável de interesse. Essa estatística possibilita identificar os regimes espaciais, os quais são agrupados em quatro categorias (quando estatisticamente significantes) com características similares. Os padrões formados são: alto-alto, baixo-baixo, alto-baixo e baixo-alto que, no contexto desse trabalho, em uma análise univariada, compara os diferentes índices de eficiência entre as microrregiões e caracteriza possíveis clusters que se formam em função dos padrões de homogeneidade ou heterogeneidade no espaço microrregional.

\section{Resultados}

\subsection{Estimativas dos modelos FPE}

Os resultados da estimação dos modelos FPE para as lavouras permanentes e temporárias são apresentados nas Tabelas 5 e 6, respectivamente. Além dos coeficientes estimados, as tabelas reportam algumas informações sobre o ajustamento dos modelos ${ }^{12}$. Incialmente serão analisados os resultados da estimação para as lavouras permanentes e, depois, para as lavouras temporárias.

Conforme os dados da Tabela 5, o Modelo 1, no qual a ineficiência é dada exclusivamente como resposta da função de produção definida, não foi estatisticamente significativo no teste LR, o que, grosso modo, indica não ser desejável uma especificação individual contra uma agrupada. Dito de outro modo, esse resultado também pode ser lido como uma incapacidade de os fatores de produção especificados na função estarem gerando sozinhos o padrão de ineficiência individual estimado. Assim, há necessidade de incorporar elementos adicionais para explicar a ineficiência. Esse exercício é feito nos Modelos

12. Na literatura de fronteiras estocásticas, o teste gama normalmente é utilizado como referência de ajuste dos modelos estimados, que consiste numa razão de variâncias dos erros dada por: $\frac{\sigma_{u}^{2}}{\sigma_{u}^{2}+\sigma_{v}^{2}}$. 
2 a 4, cujas regressões inserem elementos que podem afetar a ineficiência: variáveis relacionadas ao capital humano e concentração do sistema produtivo, temperatura, clima e biomas.

Na metodologia FPE, os coeficientes estimados representam a resposta média das variáveis ao nível de eficiência medida, sendo sua significância testada a partir do teste $t$. É importante chamar a atenção para o fato de que, no modelo original, $u_{i}$ é o valor de ineficiência e, assim, a interpretação correta das variáveis estimadas é de que sinais negativos dos coeficientes estimados estão contribuindo para aumento da eficiência, e sinais positivos estão ampliando a ineficiência. Já para as variáveis da função de produção, a interpretação é a usual e, como se trata de um modelo em logaritmos, os resultados representam elasticidades.

Analisando os dados, verifica-se que os sinais das variáveis estimadas na equação de produção são coerentes com a literatura, uma vez que se assemelham aos resultados encontrados por Vicente (2006) e Nogueira (2005), embora algumas variáveis tenham sido não significativas. Outro aspecto importante é que a inclusão de blocos de variáveis ao modelo FPE gerou ganhos do poder explicativo. A área apresentou elasticidade positiva e significativa, indicando que o tamanho da propriedade tem influência sobre o nível de produtividade. Os coeficientes revelam que o aumento da área das lavouras permanentes faz com que o produtor tenha ganhos de escala, diluindo o custo dos produtos que, independentemente da produção, demandam insumos quase-fixos. Mesmo para as culturas permanentes, que em geral requerem maior nível de trabalho manual em função de suas características, o fator trabalho mostrou-se significativo e com impacto negativo sobre o nível de produtividade, indicando que o campo tem se tornado um setor intensivo no uso do fator capital.

Os outros dois insumos de produção, mecanização e financiamento, ainda que não significativos, apresentaram sinais indicativos de que um aumento do uso de maquinário aumenta, em certa medida, o desempenho da propriedade.
Esses fatores permitem o acesso a áreas de difícil exploração e favorecem a redução do tempo necessário na execução das tarefas. Espera-se, também, que um maior acesso ao crédito faça com que os produtores ampliem sua produção, seja diretamente a partir da aquisição de insumos, seja indiretamente ao permitir maior flexibilidade na criação de uma estrutura apropriada ${ }^{13}$. Contudo, nota-se que a interação entre terra e capital apresentou elasticidade com sinal positivo e significativo, indicando que a combinação desses dois fatores aumenta a produtividade.

Quanto às variáveis que explicam diretamente ao termo de ineficiência, destaca-se que a especialização se mostrou robusta para as culturas permanentes e aponta que aquelas regiões com maior especialização produtiva (menor número de produtos cultivados) tenderam a apresentar melhor desempenho (maior eficiência), fato associado ao know-how adquirido. Já as demais variáveis mostraram significância estatística em poucos casos, apresentando, algumas vezes, sinais inesperados (como no caso de educação superior). Os biomas Cerrado e Caatinga mostraram efeitos significativos na associação com o desempenho produtivo. Destaca-se que o cultivo do café é mais expressivo no bioma Cerrado, enquanto a cultura de banana é mais expressiva no bioma Caatinga, de modo que o canal de transmissão para a eficiência das lavouras permanentes nesses biomas pode estar ligado a essas culturas. Cabe observar, ainda, que a média do índice de eficiência derivado do modelo diminui à medida que novos condicionantes são acrescentados nas especificações enquanto a variabilidade aumenta, sugerindo que esses condicionantes discriminam os diferenciais regionais de eficiência.

\footnotetext{
13. A argumentação de que o financiamento pode estar mais relacionado à produção de maneira indireta (afetando o erro não aleatório) e não como elemento de produção é possível; porém, a justificativa de seu uso aqui deve-se ao objetivo de uma função de produção que contemplasse os insumos clássicos: terra, capital e trabalho.
} 
Tabela 5. Resultados dos modelos para lavouras permanentes

\begin{tabular}{|c|c|c|c|c|}
\hline Equações & Modelo 1 & Modelo 2 & Modelo 3 & Modelo 4 \\
\hline \multicolumn{5}{|l|}{ Equação de Produção } \\
\hline Intercepto & $1,6431^{*}$ & $2,2190^{* * *}$ & $2,5109^{* * *}$ & $2,1297^{* * *}$ \\
\hline Ln A & $1,2761^{*}$ & $1,2517^{*}$ & $1,5164^{*}$ & $1,3870^{* * *}$ \\
\hline Ln K & 0,1840 & 0,1601 & 0,1151 & 0,0897 \\
\hline $\operatorname{Ln} \mathrm{T}$ & $-0,5164$ & $-0,6889^{* *}$ & $-0,8588^{* *}$ & $-0,7170^{*}$ \\
\hline Ln F & 0,1121 & 0,1101 & 0,0454 & 0,0947 \\
\hline $\operatorname{Ln} A^{2}$ & $-0,0877$ & $-0,0997$ & $-0,1873^{* * *}$ & $-0,1485$ \\
\hline Ln K ${ }^{2}$ & 0,0113 & 0,0104 & 0,0004 & $-0,0017$ \\
\hline $\operatorname{Ln~T}^{2}$ & $0,2236^{*}$ & $0,2405^{* *}$ & $0,2867^{* * *}$ & $0,2622^{* *}$ \\
\hline $\operatorname{Ln~F}^{2}$ & 0,0186 & 0,0155 & 0,0420 & 0,0314 \\
\hline $\operatorname{Ln} A^{*} \operatorname{Ln} K$ & $0,6354^{* * *}$ & $0,6448^{* * *}$ & $0,7464^{* * *}$ & $0,7229^{* * *}$ \\
\hline $\operatorname{Ln} A^{*} \operatorname{Ln} T$ & $-0,0929$ & $-0,0674$ & $-0,0675$ & $-0,0705$ \\
\hline $\operatorname{Ln} A^{*} \operatorname{Ln} F$ & $-0,2740^{* * *}$ & $-0,2694^{* * *}$ & $-0,2178^{* * *}$ & $-0,2319^{* *}$ \\
\hline $\operatorname{Ln} K^{*} \operatorname{Ln} T$ & $-0,7247^{* * *}$ & $-0,7283^{* * *}$ & $-0,7768^{* * *}$ & $-0,7545^{* * *}$ \\
\hline $\operatorname{Ln} K^{*} \operatorname{Ln} F$ & 0,0904 & 0,0912 & 0,0326 & 0,0446 \\
\hline $\operatorname{Ln} T^{*} \operatorname{Ln} F$ & 0,1884 & $0,1888^{*}$ & $0,1648^{*}$ & 0,1662 \\
\hline \multicolumn{5}{|l|}{ Equação de Ineficiência } \\
\hline Especialização & - & $-0,1094$ & $-2,6637^{* * *}$ & $-2,0532^{* * *}$ \\
\hline Ensino Fundamental & - & $0,0002^{*}$ & $0,0002^{* * *}$ & 0,0002 \\
\hline Ensino Médio & - & $-0,0012$ & $-0,0012$ & $-0,0008$ \\
\hline Formação Superior & - & 0,0020 & 0,0017 & 0,0008 \\
\hline Precipitação Verão & - & - & 0,0005 & $-0,0005$ \\
\hline Precipitação Outono & - & - & 0,0006 & $-0,0011$ \\
\hline Precipitação Inverno & - & - & 0,0016 & 0,0007 \\
\hline Precipitação Primavera & - & - & 0,0011 & 0,0019 \\
\hline Temperatura Verão & - & - & 0,0201 & 0,1084 \\
\hline Temperatura Outono & - & - & $-0,2216$ & $-0,2984^{* *}$ \\
\hline Temperatura Inverno & - & - & 0,1461 & 0,1016 \\
\hline Temperatura Primavera & - & - & $0,1187^{*}$ & 0,1605 \\
\hline Amazônia & - & - & - & $-0,2427$ \\
\hline Mata Atlântica & - & - & - & $-0,2415$ \\
\hline Caatinga & - & - & - & $-0,4589^{* *}$ \\
\hline Cerrado & - & - & - & $-0,5404^{* *}$ \\
\hline Pantanal & - & - & - & $-0,9834$ \\
\hline Gama & 0,0002 & 0,0005 & 0,0115 & 0,0032 \\
\hline LR & - & $6,5083^{* * *}$ & $58,7820^{* * *}$ & $59,6197^{* * *}$ \\
\hline Eficiência Média & 0,9897 & 0,9575 & 0,7141 & 0,7889 \\
\hline Coeficiente de Variação & 1,0522 & 1,0831 & 1,3948 & 1,2548 \\
\hline Eficiência Mínima & 0,9895 & 0,2658 & 0,1882 & 0,2306 \\
\hline Eficiência Máxima & 0,9900 & 1,0000 & 1,0000 & 1,0000 \\
\hline
\end{tabular}

Fonte: Elaborado pelos autores. *** Significância a 1\%; ** Significância a 5\%; * Significância a 10\%.

Observando os resultados para as lavouras temporárias (Tabela 6), o Modelo 1 foi o único não significativo pelo teste LR, indicando também ser desejável uma estimação agrupada contendo as equações de produção e de ineficiência. Convém observar que as lavouras temporárias representam maiores volumes de produção comparativamente às lavouras permanentes, sendo que também se encontram mais dispersas regio- nalmente devido à existência de culturas que nos últimos 30 anos ganharam maior destaque na produção nacional e no cenário internacional.

Quando analisados os parâmetros estimados para a função de produção das lavouras temporárias, percebe-se grande semelhança nos sinais dos coeficientes em relação aos observados para as lavouras permanentes. Nessas culturas também há evidência de retornos crescentes à escala 
conforme os coeficientes estimados para a variável área e evidência de que a redução do fator trabalho está associada a maiores níveis de produção. A maior necessidade das culturas temporárias por mecanização está refletida ainda no tamanho do coeficiente do fator trabalho, o qual aponta elasticidade muito maior que aquela obtida para as lavouras permanentes. Nota-se que o coeficiente da variável financiamento foi significativa para as lavouras temporárias, assim como pode-se perceber maior sensibilidade relacionada aos fatores maquinários embora este não tenha sido significativo. Adicionalmente, a elasticidade da interação entre capital e trabalho se mostrou negativa e significativa no Modelo 4, assim como a interação entre área e financiamento.

Tabela 6. Resultados dos modelos para lavouras temporárias

\begin{tabular}{|c|c|c|c|c|}
\hline Equações & Modelo 1 & Modelo 2 & Modelo 3 & Modelo 4 \\
\hline \multicolumn{5}{|l|}{ Equação de Produção } \\
\hline Intercepto & 2,6283 & $4,4743^{* * *}$ & $5,1988^{* * *}$ & $5,6057^{* * *}$ \\
\hline Ln A & 0,6667 & $1,0964^{* *}$ & $1,5955^{* *}$ & $1,2845^{* * *}$ \\
\hline Ln K & $0,6452^{*}$ & 0,4964 & 0,2450 & 0,1441 \\
\hline $\operatorname{Ln} \mathrm{T}$ & $-0,3938$ & $-1,4540^{* * *}$ & $-1,7701^{* * *}$ & $-1,8630^{* * *}$ \\
\hline Ln F & 0,3709 & $0,6173^{* *}$ & $0,6494^{* *}$ & $1,0406^{* * *}$ \\
\hline $\operatorname{Ln} A^{2}$ & $-0,2166$ & $-0,1026$ & $-0,0136$ & 0,0469 \\
\hline $\operatorname{Ln~} \mathrm{K}^{2}$ & $-0,0339$ & 0,0805 & $-0,0042$ & 0,0226 \\
\hline $\operatorname{Ln} \mathrm{T}^{2}$ & $-0,1416$ & 0,1618 & $0,2781^{* *}$ & $0,2934^{* * *}$ \\
\hline $\operatorname{Ln~F}^{2}$ & $0,1004^{* * *}$ & $0,0753^{* * *}$ & $0,0614^{* * *}$ & $0,0500^{* * *}$ \\
\hline $\operatorname{Ln} A^{*} \operatorname{Ln} \mathrm{K}$ & $0,5070^{* * *}$ & 0,1022 & 0,0524 & 0,0296 \\
\hline $\operatorname{Ln} A^{*} \operatorname{Ln} T$ & $0,4639^{*}$ & 0,1530 & $-0,0579$ & $-0,0200$ \\
\hline $\operatorname{Ln} A^{*} \operatorname{Ln} F$ & $-0,2919^{*}$ & $-0,1183$ & $-0,1615$ & $-0,2535^{* * *}$ \\
\hline $\operatorname{Ln~} K^{*} \operatorname{Ln} T$ & $-0,6729 * * *$ & $-0,2327$ & $-0,1190$ & $-0,1415^{* * *}$ \\
\hline $\operatorname{Ln} K^{*} \operatorname{Ln} F$ & $-0,0225$ & $-0,0901$ & $-0,0173$ & 0,0772 \\
\hline $\operatorname{Ln} T^{*} \operatorname{Ln} F$ & 0,1746 & $-0,0255$ & $-0,0023$ & $-0,0414$ \\
\hline \multicolumn{5}{|l|}{ Equação de Ineficiência } \\
\hline Especialização & - & $0,9143^{* * *}$ & $1,3816^{* * *}$ & 0,4381 \\
\hline Ensino Fundamental & - & $0,0001^{* *}$ & $0,0002^{* *}$ & $0,0002^{* * *}$ \\
\hline Ensino Médio & - & $0,0017^{* * *}$ & $0,0010^{*}$ & 0,0007 \\
\hline Formação Superior & - & $-0,0099 * * *$ & $-0,0115^{* * *}$ & $-0,0084^{* * *}$ \\
\hline Precipitação Verão & - & - & $-0,0152^{* * *}$ & $-0,0126^{* * *}$ \\
\hline Precipitação Outono & - & - & $0,0112^{* * *}$ & $0,0090^{* * *}$ \\
\hline Precipitação Inverno & - & - & $0,0188^{* * *}$ & $0,0165^{* * *}$ \\
\hline Precipitação Primavera & - & - & $-0,0163^{* * *}$ & $-0,0124^{* * *}$ \\
\hline Temperatura Verão & - & - & $-0,5637^{* * *}$ & $-0,5885^{* * *}$ \\
\hline Temperatura Outono & - & - & 0,1338 & 0,0426 \\
\hline Temperatura Inverno & - & - & $0,7344^{* * *}$ & $0,5762^{* * *}$ \\
\hline Temperatura Primavera & - & - & $-0,2646$ & $-0,0227$ \\
\hline Amazônia & - & - & - & $1,5227^{* * *}$ \\
\hline Mata Atlântica & - & - & - & 0,1488 \\
\hline Caatinga & - & - & - & $1,7787^{* * *}$ \\
\hline Cerrado & - & - & - & $0,9339^{* *}$ \\
\hline Pantanal & - & - & - & $-0,6351$ \\
\hline Gama & 0,0001 & 0,0009 & 0,0836 & 0,0100 \\
\hline LR & - & $73,753^{* * *}$ & $169,24^{* * *}$ & $233,49^{* * *}$ \\
\hline Eficiência Média & 0,9914 & 0,5925 & 0,1473 & 0,1079 \\
\hline Coeficiente de Variação & 1,3969 & 2,1903 & 8,1282 & 10,352 \\
\hline Eficiência Mínima & 0,9913 & 0,0057 & 0,0032 & 0,0012 \\
\hline Eficiência Máxima & 0,9915 & 1,0000 & 1,0000 & 1,0000 \\
\hline
\end{tabular}

Fonte: Elaborado pelos autores. *** Significância a 1\%; ** Significância a 5\%; * Significância a 10\%. 
Observando os resultados para a equação de ineficiência, fica claro que houve significativa melhora do poder explicativo dos modelos, ao contrário dos modelos para lavouras permanentes em que as respostas à inclusão das variáveis condicionantes da ineficiência não foram muito relevantes. Tal aspecto fica evidente ao se constatar que muitos coeficientes da equação de ineficiência são significativos no caso das lavouras temporárias e que a estatística LR, que mede a relevância da inclusão das variáveis, aumenta expressivamente do Modelo 2 ao Modelo 4.

A escolaridade do administrador da propriedade foi significativa e os sinais, de acordo com o esperado. O Ensino Superior contribui para aumentar a eficiência, enquanto que o Ensino Fundamental para redução. $\mathrm{O}$ fato de propriedades mais profissionalizadas terem ganho de eficiência indica que a escolaridade é importante para o desempenho. Já o fato de a especialização produtiva ter apresentado efeito negativo (Modelos 2 e 3) sobre a eficiência pode estar associado ao fato de que as lavouras temporárias possibilitam a utilização da terra para cultivar mais de uma cultura por ano, de modo que a especialização refletiria uma subutilização da propriedade com efeitos de perda de eficiência. Contudo, no Modelo 4 a especialização não se mostrou significativa ao incorporar os condicionantes de bioma.

Os parâmetros de chuva e temperatura médias foram significativos para o aumento da eficiência nas estações da primavera e do verão, o que pode estar relacionado às culturas de soja e cana-de-açúcar terem seu momento de plantio e floração nessas épocas, quando a chuva é importante para o desenvolvimento das plantações. Já os parâmetros de biomas, com exceção do Pantanal, apresentaram características para aumento de ineficiência, destacando-se que o pior resultado está relacionado ao bioma da Caatinga.

Além disso, à medida em que se aumentam os condicionantes entre os Modelos 2 e 4, percebe-se uma redução dos valores da eficiência média e aumento do coeficiente de variação dos índices de eficiência. Tal resultado mostra que as variáveis introduzidas no modelo explicam boa parte dos diferenciais de eficiência e, assim, permitem discriminar com maior precisão as regiões mais eficientes daquelas menos eficientes. Como consequência, isso implica no aumento da dispersão do índice de eficiência entre as microrregiões. Esse resultado é preocupante, uma vez que boa parte do desempenho agrícola parece estar mais relacionado com os fatores locacionais do que com outras características das propriedades como o nível de especialização e de escolaridade dos dirigentes.

\subsection{Análise espacial da eficiência agrícola}

Conforme os resultados da Tabela 7 , há fortes evidências da presença de dependência espacial global nos índices de eficiência tanto para as lavouras permanentes quanto temporárias. O padrão de autocorrelação espacial na eficiência é positivo, ou seja, em termos globais, unidades mais eficientes têm vizinhos mais eficientes e vice-versa. De outra forma, esses resultados podem apontar para a presença de spillovers de eficiência (difusão de boas práticas de gestão e manejo do solo, controle de pragas etc.) no espaço.

Entretanto, os valores da estatística I de Moran calculados para os modelos apresentam características diferentes entre os dois tipos de lavouras. O valor do I de Moran aumenta para as lavouras permanente à medida que novas variáveis condicionantes são acrescentadas aos modelos, enquanto que no caso das lavouras temporárias o efeito observado é decaimento do valor do I de Moran. Essa dinâmica indica que as variáveis condicionantes da equação de eficiência (especialização, escolaridade dos dirigentes e biomas) estão associados com o padrão de distribuição espacial da eficiência de maneira mais forte para o caso das lavouras temporárias do que no caso das lavouras permanentes. De certa forma, essa evidência reforça o papel das características geográficas como elemento explicativo dos diferenciais de eficiência regional para as lavouras temporárias tal como observado na seção anterior. O efeito é oposto no caso das lavouras permanentes. 
Tabela 7. Estatística I de Moran para o Índice de Eficiência

\begin{tabular}{llll}
\hline \multicolumn{1}{c}{ Equações } & Modelo 2 & Modelo 3 & Modelo 4 \\
\hline Lavouras Permanentes & $0,4581^{* * *}$ & $0,5481^{* * *}$ & $0,5910^{* * *}$ \\
Lavouras Temporárias & $0,7166^{* * *}$ & $0,5757^{* * *}$ & $0,5391^{* * *}$ \\
\hline
\end{tabular}

Fonte: Elaborado pelos autores. *** Significância a 1\%; ** Significância a 5\%; * Significância a 10\%.

A visualização dos clusters espaciais obtidos pela análise LISA (Figura 4) sustentam as conclusões acima. Para as lavouras permanentes, o padrão geral é que as áreas dos clusters se ampliam à medida que se passa do Modelo 2 para o Modelo 4, resultado coerente uma vez que a dependência global aumenta do Modelo 2 para o Modelo 4. Esse resultado traz algumas implicações interessantes, visto que a localização dessas unidades produtivas naquelas regióes específicas tem laços que vão além de fatores de produção como motivos históricos que induziram e acabaram por construir laços para que essas atividades se localizem onde estão.

Ao analisar os mapas de clusters, é possível observar alguns padrões consistentes ao longo das regiões, sendo destacado o cluster de baixa eficiência ao longo da região Norte que se define de forma mais consolidada à medida que as variáveis de controle são adicionadas na equação de ineficiência. O destaque positivo fica por conta da zona costeira da região Nordeste, a qual apresentou um cluster de alta eficiência. Nessa região tem crescido muito a produção agrícola como resultado de políticas que utilizam as águas dos rios que cortam a região como forma de superar suas deficiências hídricas. Em síntese, existem duas grandes ilhas de eficiência nas lavouras permanentes, sendo uma abrangendo os três estados do Sul e outra, a região Nordeste (Modelos 3 e 4). A região Centro-Oeste apresentou um regime espacial de alta eficiência somente no Modelo 2 e depois deixou de fazer parte dessas ilhas de eficiência. Já no caso das ilhas de ineficiência, essas se concentram no Norte e em espaços específicos das regióes Sudeste, nas áreas relacionadas predominantemente ao cultivo do café.

O cluster de alta eficiência que passa pelos três estados da região Sul tem como principais culturas a uva e a maçã, no Rio Grande do Sul e Santa Catarina, e o cultivo de café, no Paraná. Já o cluster de alta eficiência que engloba cinco estados da região Nordeste (Pernambuco, Paraíba, Rio Grande do Norte e Alagoas) está associado predominantemente à cultura da banana. Por outro lado, o cluster de baixa eficiência no sul de Minas Gerais e Espírito Santo é bastante preocupante, uma vez que, dentre as culturas permanentes nessas regiões, o cultivo do café representa mais de $90 \%$ do quantum produzido na região, indicando a necessidade de um esforço conjunto entre órgãos públicos e produtores na tentativa de melhorar o cultivo do grão. Já na região Norte, a de pior desempenho, as culturas locais são bastante dispersas, sendo observado algum destaque à produção de borracha e banana.

No caso dos regimes espaciais associados às lavouras temporárias, ocorre o contrário do que foi observado para as lavouras permanentes, pois as áreas dos clusters espaciais tendem a diminuir à medida que se passa do Modelo 2 para o Modelo 4. Percebe-se claramente que, antes de inserir novas variáveis de controle, o cluster de alta eficiência agrícola engloba Mato Grosso, Goiás, Paraná e uma parte de Minas Gerais. Porém, esse cluster se reduz consideravelmente quando novos controles são adicionados. Por outro lado, ainda que o tamanho das ilhas de (in)eficiência se reduzam conforme se ampliam as variáveis de controle, nota-se uma persistência do padrão de baixa eficiência na região Norte, bem como uma grande "mancha" localizada na quase totalidade do bioma Caatinga.

Ao considerar as culturas produzidas nos clusters encontrados, alguns padrões interessantes aparecem. O grupamento de alta produtividade localizado no Nordeste, predominantemente no estado de Pernambuco, tem $90 \%$ de seu quantum 

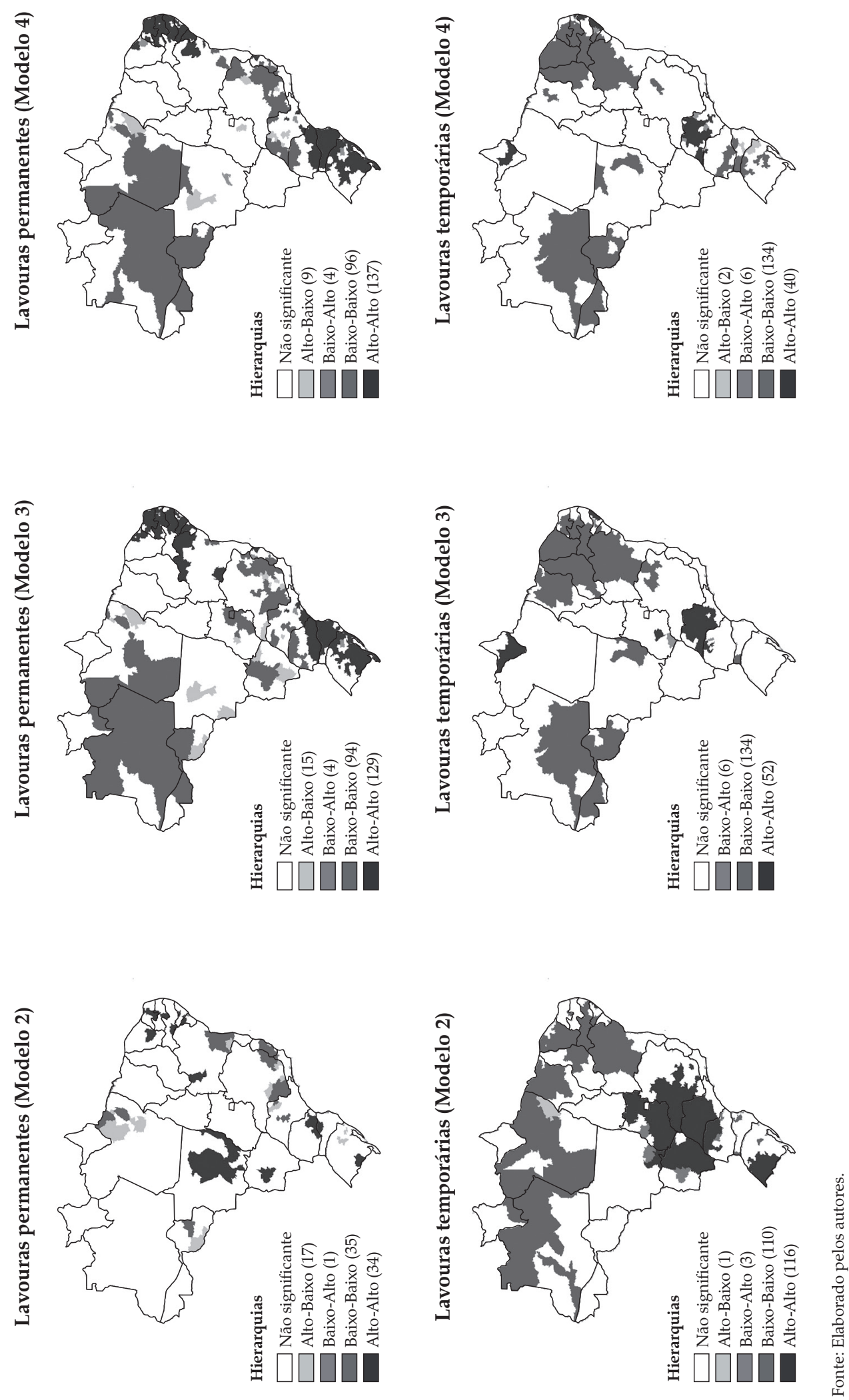
em cana-de-açúcar, assim como o que acontece com o Sudeste, mais especificadamente no estado de São Paulo, onde essa cultura representa em torno de $75 \%$ do quantum nas microrregióes envolvidas. Na região Sul, no cluster de baixa produtividade, que envolve os estados do Rio Grande do Sul, Santa Catarina e Paraná, existe um predomínio das culturas de soja (54\%) e milho (36\%). Uma possível explicação para isso é que essas regiões se caracterizam mais pela pequena propriedade, que não apresentam ganhos de escala como as grandes.

Por outro lado, o cluster de baixa eficiência que envolve praticamente toda a região Nordeste está relacionado à cultura da mandioca e do milho que, somadas, representam $70 \%$ do grupamento. Do mesmo modo, na região Norte, em especial no Amazonas, a cultura da mandioca representa $90 \%$ da produção local. Esse padrão é preocupante, uma vez que essas culturas estão tradicionalmente relacionadas à agricultura de subsistência. Também é interessante destacar, mais uma vez, que o cluster de baixa eficiência no Nordeste está associado predominantemente ao bioma da Caatinga (o qual teve o pior desempenho), no qual as restrições para a produção agrícola são notoriamente conhecidas.

\section{Considerações finais}

O principal objetivo do trabalho foi analisar o desempenho regional da agricultura brasileira para o ano censitário de 2006, combinando a análise de eficiência por meio de fronteiras de produção estocásticas e a análise espacial através de técnicas de análise exploratória de dependência espacial. Dentre os estudos realizados sobre eficiência produtiva da agricultura no Brasil, nenhum teve como enfoque a discussão sobre o padrão espacial da eficiência produtiva utilizando as microrregiões como unidade de análise. Além disso, para melhor compreensão do problema, o presente estudo considerou as culturas agrícolas permanentes e temporárias de forma separada, buscando captar especificidades que poderiam ficar ocultas caso essas culturas fossem agrupadas.
Para as culturas da lavoura permanente, destacaram-se os fatores de produção terra e trabalho como importantes sobre o nível de atividade, sendo que o primeiro se relaciona positivamente com o desempenho agrícola devido as economias de escala e o segundo se relaciona negativamente devido a ganhos decorrentes da intensidade tecnológica. A interação entre terra e capital também se mostrou importante para explicar eficiência produtiva. Além disso, constatou-se presença de dependência espacial global nos índices de (in)eficiência, aspecto que evidencia efeitos de spillovers espaciais. Os resultados da técnica LISA identificaram clusters de alta eficiência na região Sul (associado ao cultivo de uvas e maçãs) e na região Nordeste (associado ao cultivo de bananas). Por outro lado, a situação da região Norte se mostrou preocupante, já que se observa uma grande "mancha" de baixa eficiência. Também vale ser destacada a situação da região Sudeste nas áreas relacionadas ao cultivo de café, que se mostraram de baixa eficiência.

Para as lavouras temporárias destaca-se também o papel dos fatores terra e trabalho, com efeitos similares sobre o desempenho como observado nas culturas permanentes. Contudo, um aspecto importante é que as variáveis ligadas à localização geográfica (precipitações, temperatura e biomas) se mostraram mais relevantes para explicar a eficiência agrícola das lavouras temporárias do que para as lavouras permanentes. $\mathrm{Na}$ análise espacial aplicada no índice de eficiência das lavouras temporárias também se constatou dependência espacial global e local, observando-se um agrupamento de regiões de alta eficiência no Sudeste e em uma pequena fração do Nordeste, ambas relacionadas ao cultivo de cana-de-açúcar. Por outro lado, os resultados mostraram que boa parte das regiões Norte e Nordeste estão em uma área de baixa eficiência, onde predomina o cultivo relacionado a culturas de subsistência.

Quando comparados os dois modelos, também merece ser destacado que a especialização exerce influências diferentes sobre a eficiência em cada tipo de lavoura, ou seja, está associada 
a ganhos (perdas) de eficiência para as lavouras permanentes (temporárias). Enquanto as culturas permanentes exigem maior imobilização da área, as culturas temporárias possuem certa flexibilização, fazendo com que um nível elevado de especialização não seja a escolha ótima para as culturas temporárias.

Vale notar também que, em geral, o dinamismo dos setores produtivos das regiões mais pobres e estagnadas do País está fortemente vinculado com o setor primário, o qual tem o papel relevante na geração de renda e emprego nessas economias locais. Dessa forma, os resultados encontrados neste estudo reforçam a necessidade de que as políticas do setor agrícola priorizem ações de melhoria da eficiência produtiva no contexto espacial, ou seja, levando-se em conta as especificidades territoriais.

Por fim, é importante mencionar que os resultados dos modelos FPE estimados podem ser sensíveis às especificações dos modelos, sendo que a incorporação de outras variáveis poderia modificá-los. Por exemplo, não foram considerados o uso de adubos e fertilizantes, bem como o grau de concentração da terra, que também poderiam ser fatores relevantes para a eficiência agrícola. $\mathrm{O}$ mesmo vale para a regra de ponderação adotada na mensuração do quantum da produção agrícola, que utilizou o valor adicionado para calcular os pesos das culturas. Essas e outras questões deixam margem para que futuros trabalhos abarquem diferentes especificações do modelo FPE, como também abordagens econométricas longitudinais (dados em painel), a fim de trazer mais elementos para a discussão sobre a questão da eficiência agrícola no Brasil.

\section{Referências}

AIGNER, D. J., LOVELL, C. A. K. e SCHMIDT, P. Formulation and Estimation of Stochastic Frontier Production Function Models. Journal of Econometrics, v. 6, p. 21-37, 1977.

ALMEIDA, E. Econometria espacial aplicada. Campinas: Alínea, 2012.
BATTESE, G., COELLI, T. e A Model for Technical Inefficiency Effects in a Stochastic Frontier Production Function for Panel Data. Empirical Economics, v. 20, p. 325-332, 1995.

COELLI, T. J., RAO, D. S. P. e O'DONNELL, C. J. B. G. E. An Introduction to Efficiency and Productivity Analysis. New York: Springer, 2005.

COELLI, T. J. A Guide to FRONTIER Version 4.1: A Computer Program for Stochastic Frontier Production and Cost Function Estimation. CEPA Working papers, v. 7, p. 1-33, 1996.

DE FERRANTI, D. M. (Ed.). Beyond the city: the rural contribution to development. Washington: World Bank Publications, 2005.

FELEMA, J., RAIHER, A. P. e FERREIRA, C. R. Agropecuária Brasileira: desempenho regional e determinantes de produtividade. Revista de Economia e Sociologia Rural, v. 51, n. 3, p. 555-573, 2013.

FORNAZIER, A. e VIEIRA FILHO, J. E. R. Heterogeneidade estrutural no setor agropecuário brasileiro: evidências a partir do censo agropecuário de 2006. TD Ipea, n. 1708, 2012.

FRIED, H. O., LOVELL, C. A. K. e SCHMIDT, S. S. (Ed.). The Measurement of Productive Efficiency and Productivity Growth. New York: Oxford University Press, 2008.

GASQUES, J. G. Produtividade total dos fatores e transformações da agricultura brasileira: análise dos dados dos censos agropecuários. In: 48 Encontro da SOBER, 2010

HELFAND, S. M., MAGALHÃES, M. M. e RADA, N. E. Brazil's Agricultural Total Factor Productivity Growth by Farm Size. In: IDB Working Paper Series, 2015.

JOHNSTON, B. F. e MELLOR, J. W. The role of agriculture in economic development. The American Economic Review, v. 51, n. 4, p. 566-593, 1961.

JONDROW, J. et al. On the estimation of technical inefficiency in the stochastic frontier production function model. Journal of Econometrics, v. 19, n. 2-3, p. 233-238, 1982.

KUMBHAKAR, S. C. Stochastic Frontier Analysis. New York: Cambridge University Press, 2003.

MARINHO, E.; CARVALHO, R. M. Comparações interregionais da produtividade da agricultura brasileira: 19701995. Pesquisa e Planejamento Econômico, v. 34, n. 1, 2004.

MEEUSEN, W. e VAN DEN BROECK. Efficiency Estimation from CobbDouglas Production Functions with Composed Errors. International Econometric Review, v. 8, p. 435-444, 1977. 
MOREIRA, A. R. B. e FONSECA, T. C. R. Comparando Medidas de Produtividade: DEA, Fronteira de Produção Estocástica. In: TD Ipea n. 1069, 2005.

NOGUEIRA, M. A. Eficiência técnica na agropecuária das microrregiões brasileiras. Tese - Universidade Federal de Viçosa, 2005.

PEROBELLI, F. S. et al. Produtividade do setor agrícola brasileiro (1991-2003): uma análise espacial. Nova Economia, v. 17, n. 1, p. 65-91, 2007.
SCHMIDT, A. M. et al. Spatial stochastic frontier models: accounting for unobserved local determinants of inefficiency. Journal of Productivity Analysis, v. 31, n. 2, p. 101-112, 2009.

VICENTE, J. R. Comparação de produtividade agrícola entre as Unidades da Federação, 1970-1995. Agricultura em São Paulo, v. 53, n. 2, p. 69-83, 2006. 
